\title{
Peningkatan Pengetahuan Tentang Jamu Pada Siswa-Siswi di Sekolah Dasar Negeri 1 Boyolali
}

\section{Increasing Knowledge about Herbs for Students at Boyolali 1 Elementary School}

\author{
Iwan Setiawan $^{1}$, Suharyanto ${ }^{2}$, Ryan Dianto ${ }^{3}$ \\ ${ }^{1}$ Unit Farmasetika dan Teknologi Farmasi Sekolah Tinggi Ilmu Kesehatan Nasional, ${ }^{2}$ Unit \\ Kimia Analisis Sekolah Tinggi Ilmu Kesehatan Nasional \\ ${ }^{3}$ Unit Obat Tradisional Sekolah Tinggi Ilmu Kesehatan Nasional, \\ Surakarta \\ 1.iwan.setiawan02@gmail.com
}

Riwayat Artikel: Dikirim 28 September 2018; Diterima; Diterbitkan

\begin{abstract}
Abstrak
Jamu dibuat dari bahan-bahan alami, berupa bagian tumbuhan seperti rimpang (akar-akaran), daun-daunan, kulit dan batang serta buah. Sebagai suatu bentuk pengobatan tradisional, jamu memegang peranan penting dalam pengobatan penduduk negara berkembang. Litbang Depkes menginformasikan bahwa 50\% penduduk Indonesia menggunakan jamu baik untuk menjaga kesehatan maupun untuk pengobatan karena sakit. Jamu telah diterima oleh masyarakat Indonesia sebagai bagian dari pengobatan tradisional. Usia 6-12 tahun anak sudah memiliki dunia sekolah yang lebih serius walaupun ia tetap seorang anak dengan dunia yang khas, masa ini ditandai dengan perubahan dalam kemampuan dan perilaku. Pertumbuhan dan perkembangan anak membuatnya lebih siap untuk belajar dibanding sebelumnya, anak juga mengembangkan keinginan untuk melakukan berbagai hal dengan baik. Tujuan dari program pengabdian ini adalah memperkenalkan profesi ahli farmasi, memberikan pengetahuan tentang resiko mengkonsumsi minuman kesehatan dan memberikan pengetahuan tentang khasiat jamu dan obat tradisional bagi siswN 1 Boyolali Metode pengabdian dibuat menarik dengan kegiatan minum jamu bersama, mengumpulkan dan menguji pengetahuan siswa terhadap beraneka ragam tanaman obat tradisional dan penyuluhan mengenai resiko mengkonsumsi minuman kesehatan, pengetahuan tentang khasiat jamu dan obat tradisional. Pengabdian masyarakat ini diterima baik oleh pihak sekolah sehingga ditambahkan pada jadwal mingguan ada kegiatan minum susu bersama dan minum jamu bersama serta bagi anak usia dini akan sangat bermanfaat dan mampu menanamkan kecintaan anak-anak pada tanaman obat tradisional indonesia.
\end{abstract}

Kata kunci: siswa, jamu, obat tradisional

\begin{abstract}
Herbs are made of natural ingredients, such as parts of plants such as rhizomes (roots), leaves, skin and stems and fruit. As a kind of traditional medicine, herbs play an important role in curing people in developing countries. Research and Development division of the Ministry of Health states that 50\% of Indonesian people drink herbs either to keep them healthy or to recover from illness. Herbs have been accepted by Indonesian people as a part of traditional medicine. Children at the age of 6-12 years old has had more serious schooling world though their world is still distinctive. This period is signified by chances of abilities and behaviors. Growth and development of a child makes him or her more ready to learn the he or she has been in the previous stages. He or she also develop will to do things better. The program was aimed at promoting the profession of pharmacist, sharing knowledge the risk of consuming on bealthy drink and informing the benefits of drinking herbs and traditional medicine for students of Public Elementary School 1 of Boyolali. The method of the service was made interesting with drinking herbs together, collecting various kinds of traditional medicinal plants, and testing their knowledge on them and socializing the risk of consuming bealthy drinks, knowledge on the benefits of drinking herbs and traditional medicine. This community service was positively received by the school so that in the weekly schedule, drinking milk and herbs together for young children were added. And for the young children, it was really useful and able to instill the children's love to Indonesian traditional medicinal plants.
\end{abstract}

Keywords: students, herbs, traditional medicine 


\section{PENDAHULUAN}

Kata jamu telah terbiasa didengar oleh masyarakat Indonesia. Minum jamu dianggap oleh masyarakat bangsa Indonesia sebagai obat tradisional. Jamu biasanya terdiri dari tumbuh-tumbuhan dan juga dari bagian tubuh hewan. Sebagian masyarakat menyebutnya dengan pengobatan komplementer atau alternatif (complementary and alternative medicine). Di Asia, negara yang banyak menggunakan obat tradisional adalah Cina, Korea, India, dan termasuk Indonesia.

Data Riset Kesehatan Dasar (Riskesdas) 2013, suatu penelitian kesehatan berskala nasional yang diselenggarakan Badan Penelitian dan Pengembangan Kesehatan Kementerian Kesehatan, menunjukkan bahwa 30,4\% rumah tangga di Indonesia memanfaatkan pelayanan kesehatan tradisional, diantaranya $77,8 \%$ rumah tangga memanfaatkan jenis pelayanan kesehatan tradisional keterampilan tanpa alat, dan $49,0 \%$ rumah tangga memanfaatkan ramuan. Sementara itu, Riskesdas 2010 menunjukkan $60 \%$ penduduk Indonesia diatas usia 15 tahun menyatakan pernah minum jamu, dan $90 \%$ diantaranya menyatakan adanya manfaat minum jamu (Tjandra, 2014).

Menurut Soekidjo Notoatmojo (Darmawan, T. (2012)). Usia 6-12 tahun anak sudah memiliki dunia sekolah yang lebih serius walaupun ia tetap seorang anak dengan dunia yang khas, masa ini ditandai dengan perubahan dalam kemampuan dan perilaku. Pertumbuhan dan perkembangan anak membuatnya lebih siap untuk belajar dibanding sebelumnya, anak juga mengembangkan keinginan untuk melakukan berbagai hal dengan baik bahkan bila mungkin dengan sempurna.

Anak-anak cukup jarang yang mengetahui dan menyukai jamu dan tanaman obat tradisional. Padahal disekitar kita banyak sekali tanaman obat tradisional yang berkhasiat. Untuk itulah perlu mengenalkan jenis jamu dan tanaman obat tradisional dan khasiatnya bagi anak-anak siswa/i SD Negeri 1 Boyolali. Pengenalan sejak dini akan memberikan pengetahuan bahwa bukan hanya obat dari bahan kimia yang menyembuhkan. Namun, melalui tanaman herbal yang ada di kebun dan dijual di pasar dapat menyembuhkan berbagai macam penyakit. anak bisa diberikan pengetahuan jamu dan tanaman obat tradisional melalui observasi langsung. Dengan melihat, dikenalkan bau, warna dan kegunaannya. Biarkan dia melihat dan mengenali tanaman-tanamannya. Seperti tanaman salam, sambiloto, kunyit, temulawak, jati belanda, cabe jawa, mengkudu atau pace, jambu biji dan jahe merah. Selain sembilan tanaman herbal atau obat tradisional tersebut, masih banyak tanaman lain yang mempunyai khasiat pencegahan dan penyembuhan.

Sehingga Sasaran program pengabdian ini ditujukan kepada siswa/i SDN I Boyolali, yang mana dalam pertumbuhan dan perkembangan memilki kesiapan untuk belajar hal-hal yang baik. Dalam hal ini menjadi tujuan dari pengabdian masyarakat ini untuk memperkenalkan dan menanamkan pengetahuan serta manfaat mengonsumsi jamu sejak dini bagi siswa/i SD Negeri 1 Boyolali. Dengan program pengabdian ini anak dikenalkan dengan jamu dan tanaman obat tradisional dengan sehingga anak akan mau menyukai dan memanfaatkan dengan jamu dan tanaman obat tradisional.

\section{METODE}

\section{Sasaran}

Sasaran dari kegiatan program Pengabdian Masyarakat ini adalah seluruh siswa-siswi SD Negeri 1 Boyolali kelas 1 hingga kelas 6 SD Negeri 1 Boyolali.

\section{Metode Pelaksanaan}

\section{Alat dan Bahan}

Alat : Projektor, Screen Blender, Ayakan, Gelas Plastik, Wadah Air 
Minum.

Bahan : Jahe, Kencur, Gula, Air Mineral.

\section{Waktu dan Tempat Pelaksanaan}

Pelaksanaan di hari Selasa, 13 Maret 2018 di halaman dan kelas SD Negeri 1 Boyolali.

\section{Metode Pelaksanaan}

Penyuluhan secara langsung dengan metode ceramah dan tanya jawab tentang jamu dan tanaman obat tradisional, serta pelatihan dengan kegiatan pembuatan jamu, gerakan minum jamu bersama, memberikan tugas siswa/i untuk membawa tanaman obat keluarga yang telah ditentukan, mengumpulkan dan mengidentifikasi tanaman obat keluarga dan tanaman obat tradisional, mewarnai gambar obat tradisional dan pengenalan tanaman tradisional.

\section{HASIL DAN PEMBAHASAN}

Program pengabdian masyarakat dengan tema gerakan minum jamu bersama yang dilakukan di SD Negeri 1 Boyolali bertujuan untuk mengenalkan, menumbuhkan dan meningkatkan ilmu, pengetahuan dan minat anak-anak terhadap jamu. Kegiatan pengenalan jamu meliputi gerakan minum jamu bersama, pengenalan TOGA (Tanaman Obat Keluarga), pemberian materi tentang jamu, peracikan jamu dan workshop tentang resiko konsumsi minuman kesehatan dan khasiat obat tradisional jamu yang diikuti oleh peserta dari siswa kelas 4,5,6 SD Negeri I Boyolali. Berdasarkan hasil observasi dan wawancara dengan guru, kepala sekolah SD Negeri 1 Boyolali sebelum kegiatan diperoleh beberapa fakta sebagai berikut:

1. Belum pernah dilakukan program serupa di SD Negeri 1 Boyolali yakni pengenalan jamu dan obat tradisional.

2. Kegiatan minum susu menjadi kegiatan rutin disekolah yang dilaksanakan setiap minggu.

3. SD Negeri 1 boyolali tidak lama ini menempati bangunan baru, sehingga halaman sekolah masih belum banyak terisi tanaman dan seperti pada umumnya ditanami dengan tanaman hias.

Gambar 1:

Kegiatan Minum Jamu Bersama di halaman sekolah SD Negeri 1 Boyolali
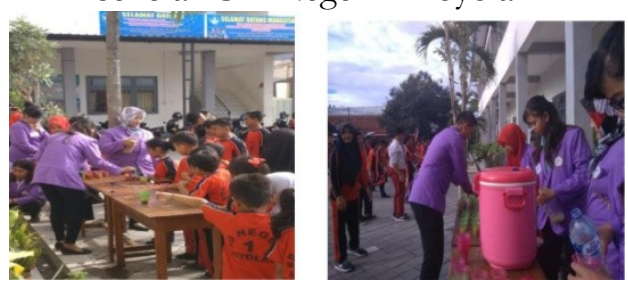

Gerakan minum jamu bersama dilakukan setelah mengikuti olahraga. Gerakan minum jamu bersama ini untuk memperkenalkan dan mengedukasi siswasiswi SD Negeri I Boyolali akan pentingnya minum jamu sejak dini dan menanamkan kesukaan mengonsumsi jamu. pada saat mereka dewasa. Gerakan minum jamu bersama dapat menjalankan budaya bangsa Indonesia mengenai jamu sebagai warisan budaya.

Kegiatan kedua dalam program pengabdian masyarakat tentang pengenalan jamu setelah minum jamu bersama dilakukan dengan berbagai metode dengan berbagai macam jenis kegiatan yang disesuaikan dengan tingkatan kelas. Hal ini dilakukan karena setiap tingkatan kelas mempunyai kemampuan yang berbedabeda dalam penerimaan materi. Jumlah siswa yang mengkuti kegiatan adalah sebanyak 250 siswa, dari kelas 1 sampai kelas 6 SD Negeri 1 Boyolali. Metode pengenalan tanaman obat tradisional untuk siswa kelas 1-3 yaitu dengan mewarnai dengan konsep gambar tentang jamu. Hal ini bertujuan agar siswa kelas 1 sampai 3 dapat menerima materi yang disampaikan yaitu materi tentang jamu dengan mewarnai, selain mereka mampu menerima materi yang disampaikan juga menumbuhkan kreatifitas anak-anak terhadap seni mewarnai.

Siswa kelas 4 dan 5 diberikan materi pengenalan tentang jamu dengan tingkatan yang lebih sulit dibandingkan dengan siswa kelas 1 sampai 3 yaitu 
pemberian materi tentang Tanaman Obat Keluarga (TOGA) di mana sebelum dilakukan kegiatan siswa kelas 4 dan 5 sebelumnya diberikan materi tentang TOGA. Pelaksanaan kegiatan dilakukan dengan mencocokkan nama dengan tanaman obat, dari kelas 4 dan 5 dibagi menjadi 4 kelompok besar dengan tujuan untuk memudahkan proses pelaksanaan kegiatan serta untuk menumbuhkan nilai diskusi bagi siswa untuk melaksanakan tugas yang diberikan oleh mahasiswa penanggung jawab. Setiap siswa diberikan tugas untuk membawa tanaman obat yang telah ditentukan oleh tim pengabdian, dari tanaman obat yang telah dibawa masingmasing siswa diberikan permainan yaitu mencocokkan nama tanaman obat dengan tanaman obat yang mereka bawa serta fungsi dari tanaman obat. Kegiatan pengenalan jamu dengan pemberian materi tentang tanaman obat keluarga ini bertujuan untuk memberikan materi kepada siswa kelas 4 dan 5 SD Negeri I Boyolali, tanaman apa saja yang termasuk dalam kategori TOGA dengan harapan mereka dapat menyampaikan kepada minimal keluarga mereka tentang tanaman yang berkhasiat sebagai obat yang bisa ditanam di lingkungan keluarga.

Siswa kelas 6 diberikan materi pengenalan tentang jamu yaitu dengan pemberian materi dasar tentang jamu yang meliputi tebak nama simplisia basah dengan mata tertutup, peracikan jamu yaitu wedang uwuh dan dilakukan post test tentang materi yang telah disampaikan. Pelaksanaan kegiatan dilakukan dengan pembagian kelompok menjadi 6 kelompok, hal ini bertujuan untuk memudahkan proses pelaksanaan kegiatan serta menumbuhkan nilai diskusi pada siswa kelas 6 tentang materi yang disampaikan. Sebelum pelaksanaan kegiatan siswa diberikan materi tentang jamu yaitu dengan mengenalkan kepada siswa kelas 6 tentang simplisia basah dan materi yang meliputi organoleptis dari simplisia basah. Selanjutnya materi tentang peracikan wedang uwuh yang dilakukan tiap kelompok. Hasil yang dinilai meliputi ketepatan rasa yang pas untuk wedang uwuh. Kegiatan selanjutnya untuk siswa kelas 6 yaitu dilakukan post test untuk mengetahui tingkat pengetahuan setelah pelaksanaan penyuluhan dan pelatihan.

Gambar 2:

Penyuluhan oleh Bp Iwan Setiawan, M.Sc., Apt

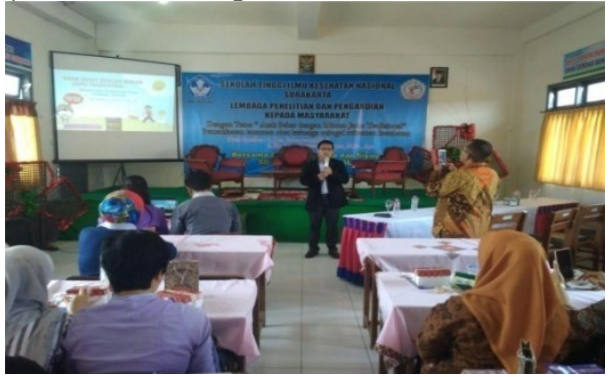

Program pengabdian masyarakat tentang pengenalan jamu yaitu dilakukan penyuluhan yang diikuti oleh seluruh siswa kelas 4,5,6. tentang kegunaan dari jamu dan obat tradisional. Pelaksanaan kegiatan penyuluhan dilakukan dengan pembekalan materi tentang jamu kepada murid SD Negeri I Boyolali yang dilakukan dengan metode ceramah dan sesi tanya jawab, hal ini bertujuan untuk menunjukkan keaktifan dari peserta serta pemahaman para peserta terhadap materi yang telah diberikan. Pada sesi tanya jawab siswa/i sangat antusias bertanya kepada narasumber tentang materi jamu dan tanaman obat tradisional.

Setelah pelaksanaan pengabdian masyarakat peningkatan pengetahuan tentang jamu, siswa/i SD Negeri 1 Boyolali terlihat antusias dan berminat terhadap jamu dan obat tradisional. Hal ini ditunjukkan dengan banyaknya siswa yang bertanya pada saat pelatihan dan penyuluhan. Keberhasilan pelaksanaan ini dapat dikarenakan faktor-faktor pendukung antara lain seperti:

1. Metode pengabdian yang yang digunakan cukup efektif menarik minat siswa/i yaitu dengan metode permainan yang interaktif seperti mewarnai gambar dengan tema jamu dan obat tradisional, permainan menebak 
tanaman obat tradisional dengan mata tertutup, menyebutkan nama dan khasiat, serta menebak dan menyebutkan bagian-bagian dari tanaman obat tradisional.

2. Pihak sekolah sangat kooperatif dan membantu mempersiapkan tempat pelaksanaan yang kondusif seperti halaman, kelas serta kelengkapan sarana lcd proyektor dan pengeras suara.

3. Siswa/i SD Negeri 1 yang sangat proaktif dan bersemangat dalam mengerjakan tugas yang diberikan.

4. Dosen sebagai nara sumber sangat menguasai topik yang diberikan dalam pengabdian.

Namun selama pelaksanaan tetap ditemukan berbagai kendala-kendala seperti:

1. Waktu pelaksanaan kegiatan dari pukul 07.00 pagi hingga pukul 15.00 dirasakan masih sangatlah kurang untuk memberikan pemahaman dan pengetahuan yang lebih mendalam mengenai jamu dan obat tradisional bagi siswa/i.

2. Anggaran kegiatan kurang mencukupi untuk menambah jumlah doorprize dan hadiah sebagai apresiasi bagi siswa/i agar meningkatkan motivasi dan semangat siswa/i.

\section{KESIMPULAN}

Dari kegiatan pengabdian ini diperoleh kesimpulan sebagai berikut:

1. Meningkatnya pengetahuan Siswasiswi SD Negeri 1 Boyolali tentang informasi dan khasiat jamu dan tanaman obat tradisional yang ditunjukkan kenaikan nilai hasil post test setelah pelaksanaan kegiatan.

2. Meningkatnya minat Siswa-siswi SD Negeri 1 Boyolali tentang informasi dan khasiat jamu dan tanaman obat tradisional yang ditunjukkan tinggi minat dan banyaknya siswa yang bertanya.

\section{UCAPAN TERIMA KASIH}

Peneliti mengucapkan terima kasih kepada:

1. Ketua Sekolah Tinggi Ilmu Kesehatan Nasional atas dukungan yang diberikan.

2. Kepala Sekolah Dasar Negeri 1 Boyolali yang sudah menerima dan membantu terlaksananya pengabdian ini.

3. Ketua Lembaga Penelitian dan Pengabdian Sekolah Tinggi Ilmu Kesehatan Nasional yang telah memberikan bantuan dana untuk melaksanakan pengabdian ini.

\section{DAFTAR PUSTAKA}

Badan POM RI. (2010). Acuan Sediaan Herbal Volume Kelima Edisi Pertama, Badan Pengawas Obat dan Makanan Republik Indonesia.

Dalimartha S. (2007). Atlas Tumbuhan Obat Indonesia Jilid 4. Jakarta: Puspa Swara.

Depkes R.I. (1971). Materia Medika Indonesia. Jilid III. hal. 21-25.

Depkes RI. (2008) Farmakope Herbal Indonesia Ed 1, Departemen Kesehatan Republik Indonesia

Dermawan, Deden. (2012). Buku Ajar Keperawatan Komunitas. Yogyakarta: Goysen Publishing.

Hariana, A. (2007). Tumbuban obat dan khasiatnya. Seri 3. Jakarta: Penebar Swadaya.

Tjandra Y. A. (2014). Jamu \& Kesehatan. Jakarta: Badan Penelitian dan Pengembangan Kesehatan. 